\title{
Article \\ Novel Deployable Panel Structure Integrated with Thick Origami and Morphing Bistable Composite Structures
}

\author{
Shuyong Ding ${ }^{1}{ }^{\oplus}$, Min Sun ${ }^{2,3}{ }^{\oplus}$, Yang $\mathrm{Li}^{2}$, Weili Ma ${ }^{2}$ and Zheng Zhang ${ }^{2,3, *}$ \\ 1 Zhijiang College of Zhejiang University of Technology, Shaoxing 312030, China; dsy@zjc.zjut.edu.cn \\ 2 College of Mechanical Engineering, Zhejiang University of Technology, Hangzhou 310014, China; \\ sunmin@zjut.edu.cn (M.S.); 18989492565@163.com (Y.L.); 15957178549@163.com (W.M.) \\ 3 Key Laboratory of Special Purpose Equipment and Advanced Processing Technology, Ministry of Education \\ and Zhejiang Province, Zhejiang University of Technology, Hangzhou 310014, China \\ * Correspondence: zzhangme@zjut.edu.cn
}

check for

updates

Citation: Ding, S.; Sun, M.; Li, Y.; Ma, W.; Zhang, Z. Novel Deployable Panel Structure Integrated with Thick Origami and Morphing Bistable Composite Structures. Materials 2022, 15, 1942. https://doi.org/10.3390/ ma15051942

Received: 6 February 2022

Accepted: 2 March 2022

Published: 5 March 2022

Publisher's Note: MDPI stays neutral with regard to jurisdictional claims in published maps and institutional affiliations.

Copyright: (C) 2022 by the authors. Licensee MDPI, Basel, Switzerland. This article is an open access article distributed under the terms and conditions of the Creative Commons Attribution (CC BY) license (https:// creativecommons.org/licenses/by/ $4.0 /)$.

\begin{abstract}
This paper proposes a novel deployable panel structure integrated with a bistable composite structure and thick panel based on the thick origami technique. To overcome the interference effects between thick panels, the axis shift method is used in this deployable structure design. Bistable composite structures are employed as hinges for morphing characteristics. The trigger force and load-displacement curves of the structure are obtained by experiments and numerical simulations. The factors that affect the coverage area-to-package volume ratio and trigger force are discussed. The experimental and numerical results verify that the structure has two stable configurations and a large coverage area-to-package volume ratio.
\end{abstract}

Keywords: origami structure; deployable bistable structure; finite element analysis; mechanical testing; assembly

\section{Introduction}

A deployable structure has the capacity to transform and predictably adopt multiple predetermined configurations, moving through known paths while deploying in a controlled and safe way [1]. Deployable structures have been defined as convertible structures with the capacity to undergo large configuration changes in an autonomous manner [2], and the reverse process is called retraction. There are some deployable structures that can maintain static equilibrium at each stage of deployment [3,4], thereby offering an even greater range of adaptability. The shape, properties and behavior of deployable structures can be changed to adapt to their surroundings and specific application environments [5]. A deployable structure is a mobile assembly that does not target motion but attains different configurations depending on the service requirements. Deployable structures can use mechanisms to achieve their changing circumstances, such as their shape or function [6]. At a basic level, a deployable structure is a kind of spatial structure formed by plates or sticks based on different configurations in space [7]. Deployment refers to the transformation of these structures from small, tight and compact configurations to unfolded and open configurations with load-carrying capacity [8,9]. These structures are primarily used for transportation purposes or applications requiring shape adaptability, such as a solar panel [10], which allows more panels to be in direct sunlight at any given point, facilitating power generation.

Origami is the ancient art of folding paper, where a two-dimensional structure is realized into complex, three-dimensional configurations. Origami technology has become a research hotspot in the aerospace [11], bionic structure [12-14] and microrobotics [15,16] fields. Many novel and practical folding methods have been designed and developed, among which the Miura pattern is the most pioneering and common folding method $[17,18]$. A comprehensive experimental and analytical study on the dynamics of origami folding by 
investigating a stacked Miura origami structure with intrinsic bistability has been presented by Fang et al. [19]. This study provides fundamental insights into the dynamics of origami folding and provides a solid foundation for developing foldable and deployable structures. Apart from the above methods, there are several more common folding methods, such as waterbomb [20,21], which is a single-vertex, bistable mechanism with unique properties for smart materials and control systems. Hanna et al. [22] report a quantitative investigation of the kinetic behavior of a symmetric waterbomb base. The multiforming of the origami structure can be obtained by folding the panel along the crease; nevertheless, the state of the origami structure is unstable when the deformation is completed or the stability tends to be destroyed. Chillara and Dapino [23] propose a strategy for the creation of smooth folds in finite-thickness laminated composites; this approach is applicable to smart, folding structures with reconfigurable creases inspired by origami technology.

A bistable composite structure has two different stable configurations without the need for a continuous external energy supply [24-26]. This smart structure has great practical value and wide application in deployable structures [27,28], mechanical engineering [29,30] and even biological engineering fields [31,32]. Generally, bistable composite structures can be divided into two categories according to their stacking sequence. The first one is named the cross-ply composite structure [33-35], which has been comprehensively studied. The effect of the initial curvature of the tool plate on the snap-through load of a square cross-ply bistable composite was analyzed in a previous study [36]. A cross-ply bistable composite structure transforms between two stable states once subjected to a small given load, which means it has a low load-carrying capacity. Therefore, another bistable composite structure, named the anti-symmetric composite structure [37,38], has been proposed. The main characteristics of anti-symmetric layup that differ from the cross-ply layup are as follows: (1) the force to trigger the snap-through and snap-back processes of the anti-symmetric structure is higher than that of the cross-ply structure; (2) the two different configurations of the cross-ply structure have opposite directions, while the directions of two stable shapes for anti-symmetric structures are the same. Zhang et al. [37,39] comprehensively investigate this novel structure by considering temperature effects [37], hygroscopic influences and viscoelastic properties. As a stable deployable panel structure is expected, anti-symmetric layups have been selected in this study.

This paper presents a deployable panel structure strategy by combining the bistable structure and thick panel. The deployable structure is proposed based on the principle of thick origami for specimen manufacturing and numerical simulation. The specimens of the deployable panel structure have been designed and manufactured according to the thick origami technique, and experiments have been conducted to investigate the trigger force and load-displacement curves. Finally, finite element (FE) simulation of the morphing process has been conducted by using ABAQUS software. The results of the numerical simulation and experimental test are compared and found to be in good agreement.

\section{Design of the Deployable Panel Structure}

In this section, a deployable panel with bistable anti-symmetric carbon fiber-reinforced polymer (CFRP) shells and a thick origami technique is designed and assembled, as shown in Figure 1a,b, which includes the design scheme, to solve the folding problem caused by a thick panel. 


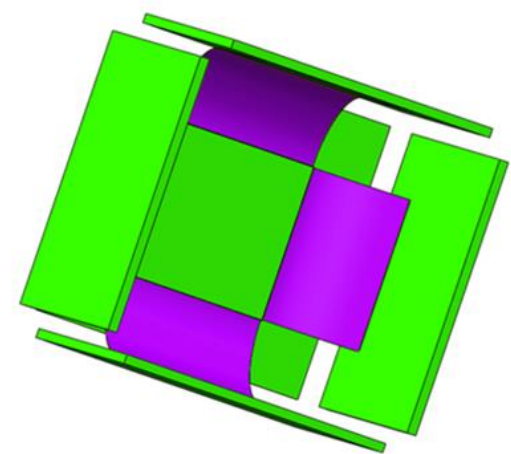

(a)

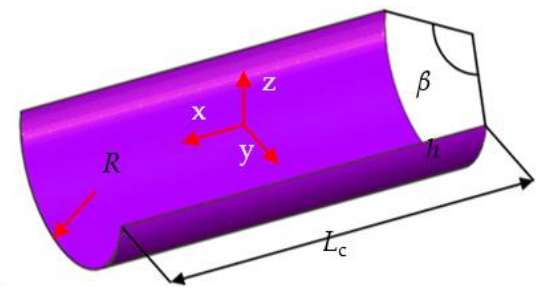

(c)

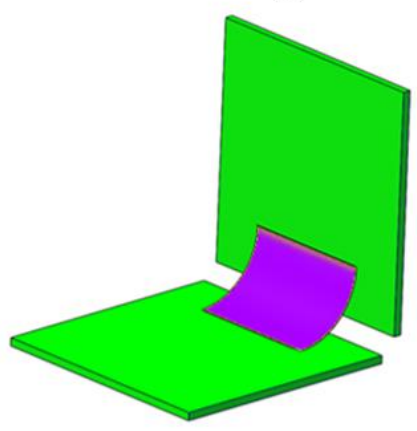

(e)

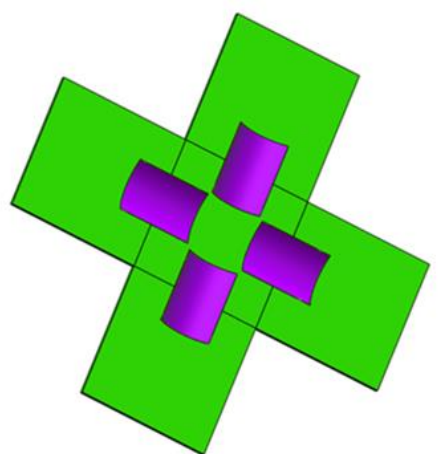

(b)

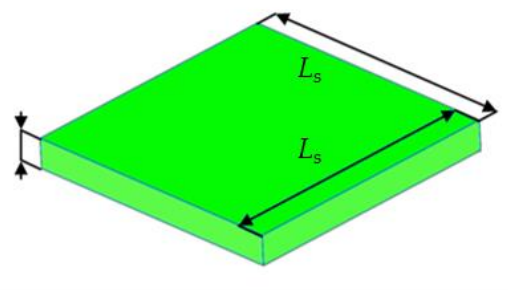

(d)

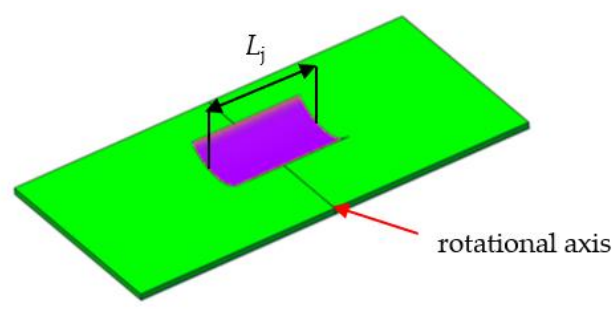

(f)

Figure 1. Three-dimensional model of the deployable panel model. (a) whole model; (b) core components of the deployable panel model; (c) cylindrical shell; (d) deployable panel; (e) folded configuration of one quarter of the deployable panel model; (f) flattened configuration of one quarter of the deployable panel model.

As a deployable structure, the panel model should have a certain capability to change in volume and surface area. As shown in Figure 1c,d, the deployable model mainly includes two parts: the deployable panel and the control unit (anti-symmetric CFRP cylindrical shell here). Inspired by the origami [40] technique, the movement of the panel has been designed to rotate around the crease. As the thickness of the panel increases, interference effects are generated during the folding of the structure. Several solutions, such as the tapered panel technique, offset panel technique, hinge shift technique and rolling contacts technique, have been developed to overcome this problem. The axis shift method is adopted in this paper because the integrity of the deployable panel model can be guaranteed in this situation.

An overlapping region occurs for deployable structures with thick panels, and it is crucial to address this issue before these structures can be realized as deformable or morphing structures. In terms of the appearance and integrity of the structure, the axis shift method is used to make the deployable structure with thick panels. To prevent collisions between the panels, each rotational axis is shifted to the top of the thick panel instead of the mid-surface as the thickness increases. In this case, the thick panel can only be folded along a fixed direction; therefore, a novel structure with one drilling degree of freedom is required as a rotational axis. The bistable CFRP cylindrical shell is employed as the hinge to realize the folding action of the entire model. 
The model transforms from the folded configuration to the flattened configuration under the action of external loading. The magnitude of the required external force to drive the model should be determined. As this model is symmetric in terms of the structure, one quarter of the model is selected as the research object, as shown in Figure 1e,f. To investigate the mechanical properties of this deployable model, experiments and finite element simulations are carried out. The geometric parameters and material parameters of the deployable panel model are given in Tables 1 and 2, respectively. The central angle of the cylindrical shell is denoted as $\beta, L_{\mathrm{c}}$ is the length of the cylindrical shell, $R$ is the radius of the cylindrical shell and $L_{\mathrm{j}}$ is the distance between two junctions. $L_{\mathrm{S}}$ is the sidelength of the deployable panel, and the thicknesses of the deployable panel and cylindrical shell are labeled $h$ and $t$, respectively.

Table 1. Material properties of the cylindrical shell.

\begin{tabular}{|c|c|c|c|c|c|c|}
\hline $\begin{array}{c}\text { Longitudinal } \\
\text { Modulus } \\
E_{11} \text { (GPa) }\end{array}$ & $\begin{array}{l}\text { Transverse } \\
\text { Modulus } \\
E_{22}(\mathrm{GPa})\end{array}$ & $\begin{array}{c}\text { Shear } \\
\text { Modulus in } \\
\text { the 1-2 Plane } \\
G_{12}(\mathrm{GPa})\end{array}$ & $\begin{array}{c}\text { Shear } \\
\text { Modulus in } \\
\text { the 1-3 Plane } \\
G_{13}(\mathrm{GPa})\end{array}$ & $\begin{array}{c}\text { Shear } \\
\text { Modulus in } \\
\text { the 2-3 Plane } \\
G_{23}(\mathrm{GPa})\end{array}$ & $\begin{array}{c}\text { Poisson Ratio } \\
v_{12}\end{array}$ & $\begin{array}{c}\text { Single Layer } \\
\text { Thickness } \\
t(\mathrm{~mm})\end{array}$ \\
\hline 132 & 10.3 & 6.5 & 6.5 & 3.9 & 0.25 & 0.12 \\
\hline
\end{tabular}

Table 2. Geometric parameters of the deployable panel model.

\begin{tabular}{cccccc}
\hline $\begin{array}{c}\text { Length of the } \\
\text { Cylindrical Shell } \\
\boldsymbol{L}_{\boldsymbol{c}}(\mathbf{m m})\end{array}$ & $\begin{array}{c}\text { Central Angle } \\
\boldsymbol{\beta}\left({ }^{\circ}\right)\end{array}$ & $\begin{array}{c}\text { Radius } \\
\boldsymbol{R}(\mathbf{m m})\end{array}$ & $\begin{array}{c}\text { Sidelength of the } \\
\text { Deployable Panel } \\
\boldsymbol{L}_{\boldsymbol{s}}(\mathbf{m m})\end{array}$ & $\begin{array}{c}\text { Thickness of the } \\
\text { Deployable Panel } \\
\boldsymbol{h}(\mathbf{m m})\end{array}$ & $\begin{array}{c}\text { Distance between } \\
\text { Two Junctions } \\
\boldsymbol{L}_{\mathbf{j}}(\mathbf{m m})\end{array}$ \\
\hline 50 & 90 & 25 & 90 & 3 & 39.25 \\
\hline
\end{tabular}

The origami technology used in this article can convert two-dimensional planar structures into three-dimensional structures, accompanied by large changes in surface area and contained volume. In recent years, it has been deeply researched, attracting great attention in the fields of deformable structure, energy collection, architecture and even bionics. In this paper, a novel solar panel structure is investigated by combining bistable shells with origami techniques.

\section{Experimental Test and FE Simulation}

Experimental tests and corresponding numerical simulations were performed on the deforming process of the deployable panel model in this section. The trigger force required for the stable transformation of the deployable structure was measured through experiments and the finite element software ABAQUS.

\subsection{Measurement of the Trigger Force}

To investigate the mechanical properties of the deployable panel model by the experimental method, a prototype of the model was designed and manufactured. The components of the deployable panel model were assembled according to the three-dimensional model, as shown in Figure 1. As discussed in the former section, a bistable CFRP cylindrical shell was selected as the actuator and control unit of the deployable structure. The stacking sequence of the CFRP cylindrical shell was $\left[45^{\circ} /-45^{\circ} / 45^{\circ} /-45^{\circ}\right]$. The CFRP cylindrical shell and the panel were bonded together by using the screw connection shown in Figure 2. Cardboard sheets with a thickness of $3 \mathrm{~mm}$ were chosen as the rigid panels and bolted together. The cylindrical shells were fabricated in a cylindrical steel mold, cured at a high temperature $180^{\circ} \mathrm{C}$ and then cooled to room temperature. The deployable panel model can maintain a flattened state and a cubic configuration in the folded state without an ongoing external energy supply. 


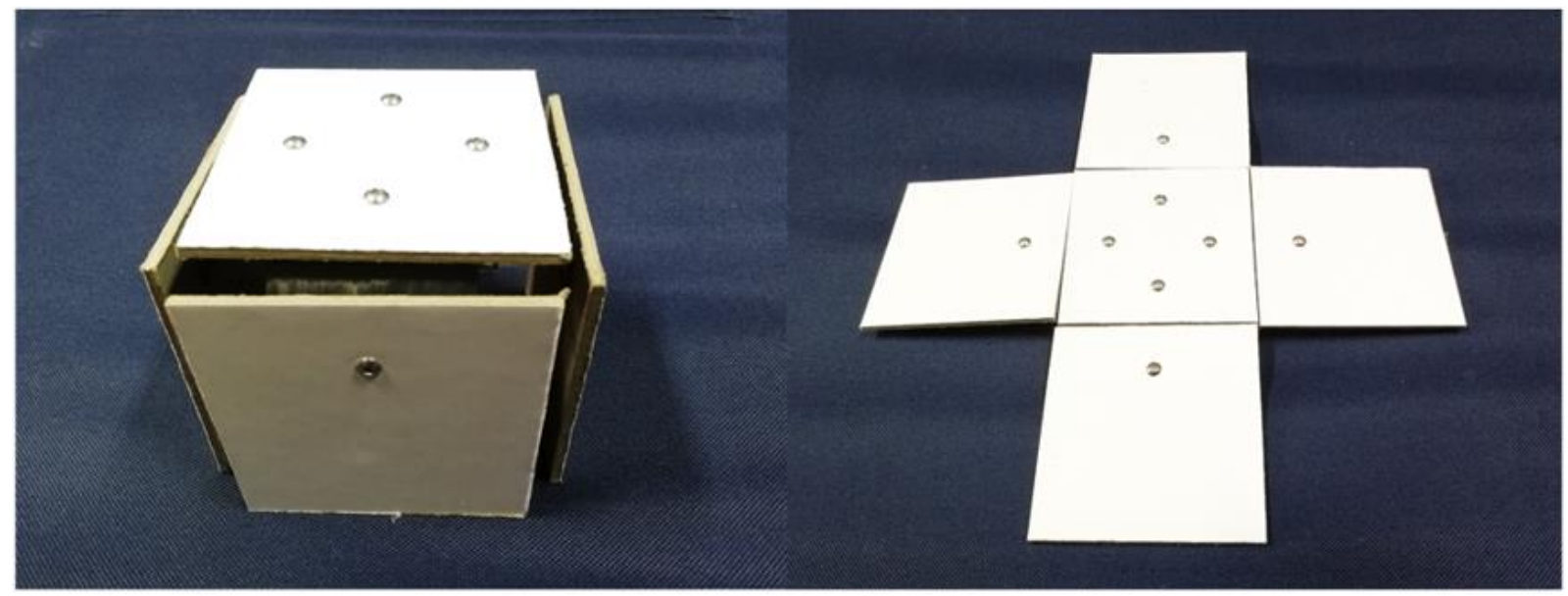

(a)

(b)

Figure 2. Different stable configurations of the specimen. (a) folded configuration; (b) flattened configuration.

The deformation process and trigger force of the deployable panel specimen were experimentally observed and measured by the universal tensile testing machine, as shown in Figure 3. The specimen was placed on the support, and the indenter moved downward. The related parameters of the universal tensile testing machine are listed as follows: (1) because the trigger force of the deployable structure is small [39], the force sensor with a measurement range of $0 \sim 50 \mathrm{~N}$ was selected; (2) the accuracy of the testing machine was less than $0.5 \%$. Interruption conditions should be established to guarantee the safety of the equipment because the second configuration of the model was a planar structure and could lead to overload. Thus, loading would be interrupted under the following conditions: (1) an abrupt decrease in the reaction force is captured, which means that the snap-through process is completed; (2) the reaction force exceeds $10 \mathrm{~N}$. Moreover, the loading speed in this experiment was $5 \mathrm{~mm} / \mathrm{min}$. The load-displacement relationship could be captured and displayed in the monitor.

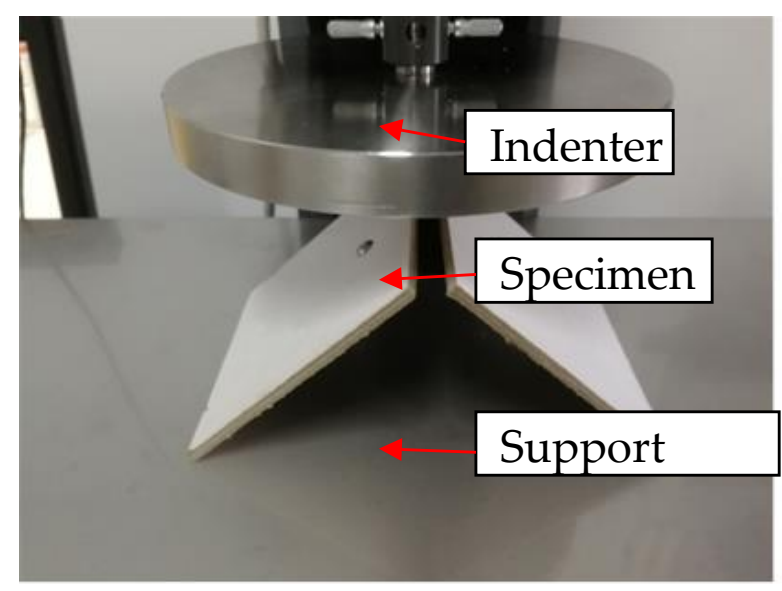

(a)

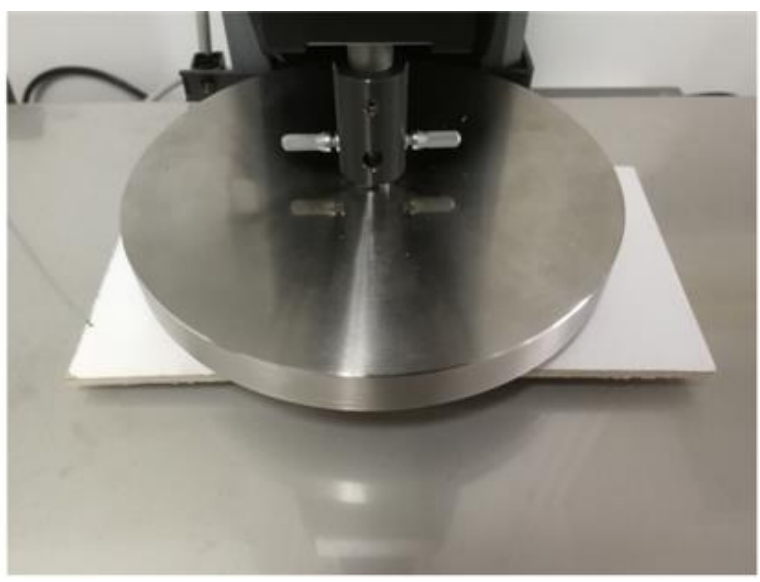

(b)

Figure 3. Experimental test platform. (a) Folded configuration; (b) flattened configuration.

The preparation of the cylindrical shell adopted the traditional autoclave process. First, the carbon fiber prepreg was laid on the cylindrical mold according to a specific layup method, and then the entire mold was packaged in a vacuum bag to ensure that the carbon fiber did not come into contact with air during high-temperature and high-pressure curing 
in an autoclave. The mold was solidified under high temperature and high pressure for three hours and then cooled to room temperature to obtain a bistable cylindrical shell. The critical load of the solar panel was tested by the Instron tensile testing machine

\subsection{Numerical Simulation}

In this section, numerical simulation of the deformation of the deployable panel model was conducted by using the finite element software ABAQUS, version 6.13. The finite element model was composed of three core components: (1) the panel (created as a rigid part), (2) the CFRP cylindrical shell (created by the composite option) and (3) the smooth support panel (created as a rigid part). The material properties of the cylindrical shell are given in Table 1. The geometric parameters of the CFRP cylindrical shell and deployable panel are listed in Table 2. Figure 4 shows the assembly relation of one quarter of the deployable panel model. The CFRP cylindrical shell was bound to the deployable panel at the junctions by the Tie option. Hard contact was established between the panel and CFRP cylindrical shell. This relationship was also applied to the interface between the support panel and the panel of the deployable structure. Two static steps were established: the loading step and the unloading step. To obtain a convergent solution, both the Nlgeom and autostabilization options were turned on. A displacement load was applied on the top edges of the deployable panel model in the loading step, which was then withdrawn in the unloading step. The corresponding boundary conditions are given as follows: six degrees of freedom of the support panel were constrained. The FE model of the shell was meshed by 1100 S4R elements.

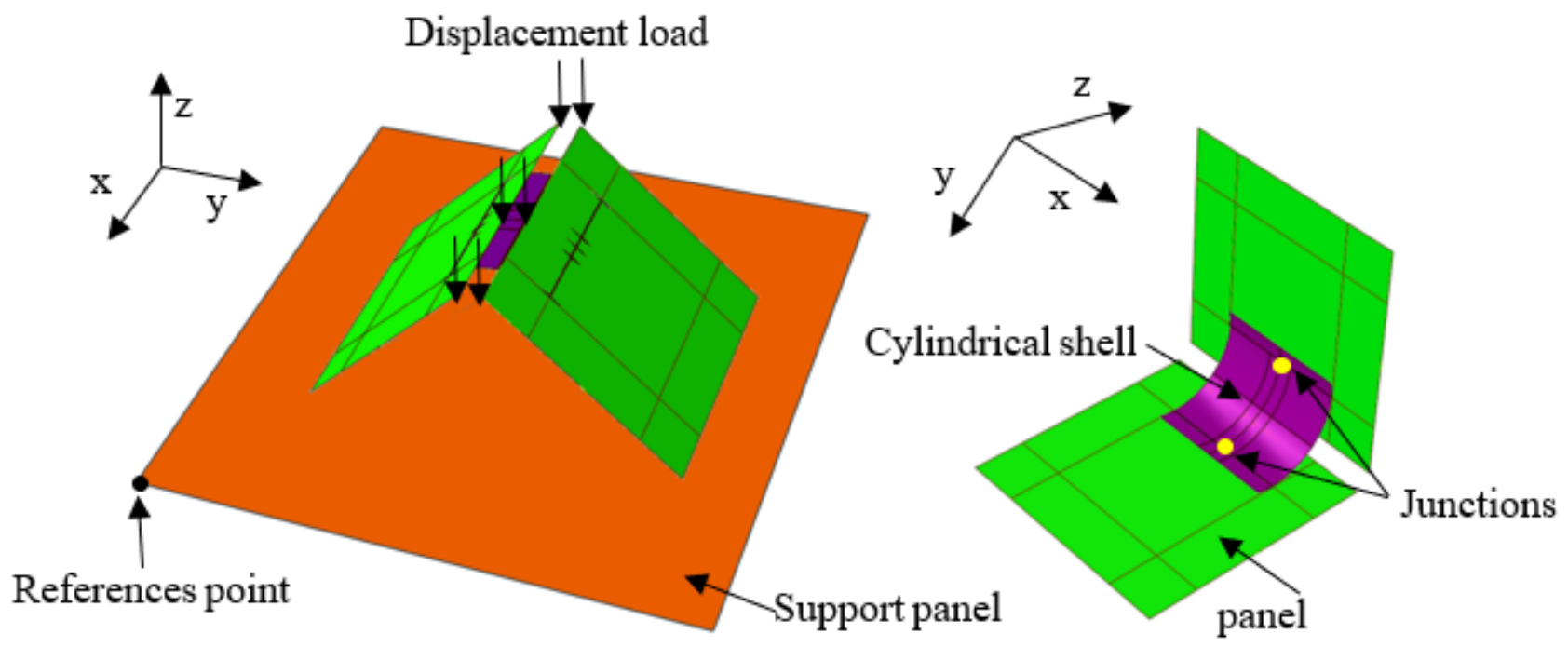

View I

View II

Figure 4. Finite element model of one quarter of the deployable panel model with bistable cylindrical shells.

Figure 5 shows the deformation process of the deployable panel model. Figure 5a indicates that the model is in the folded state; the model begins to deform as shown in Figure $5 b$; the configuration of the model in Figure $5 c$ is unstable and ready to snap-through; Figure $5 \mathrm{~d}$ shows that the snap-through process is completed and the model is in the second stable configuration; as shown in Figure 5e, to obtain a convergent solution, the position of the loaded edge exceeds the location where the second stable state is completed. The model began to recover under the effect of the CFRP cylindrical shell when the displacement load was withdrawn. Figure $5 \mathrm{f}$ shows that the model could remain in the second stable configuration without a sustained external energy supply. 
<smiles>[Y]C([Y])[14CH3]</smiles>

View I

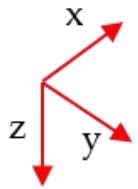

View II<smiles>[Y]C([Y])[14CH3]</smiles>

View I

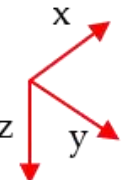

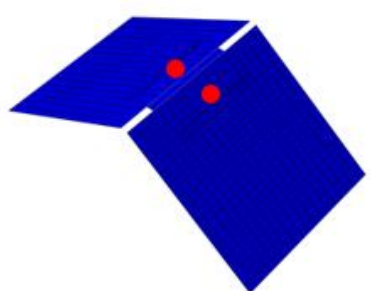

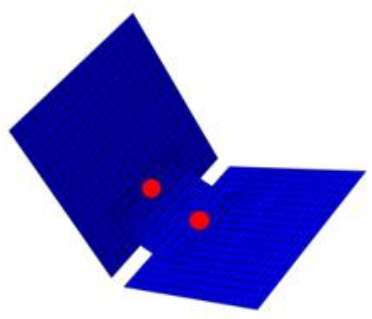

(a)
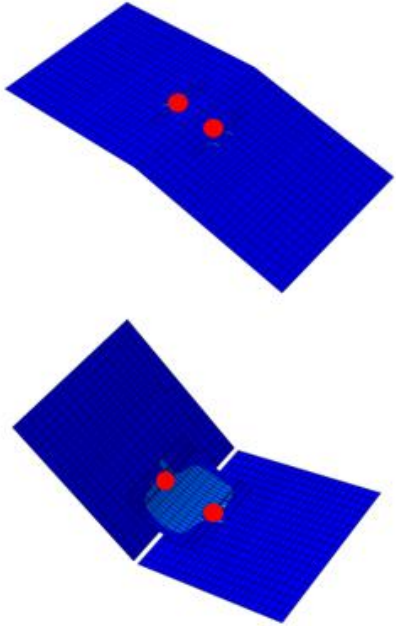

(b)

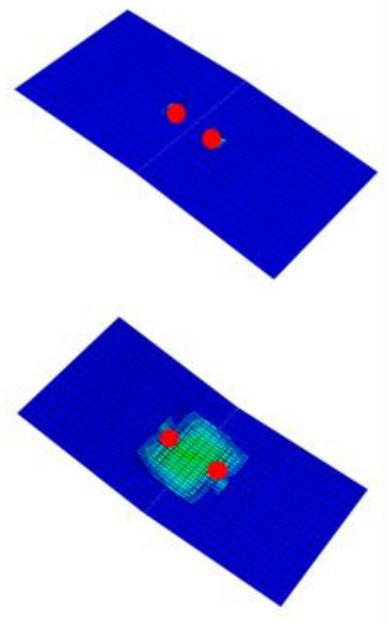

(c)
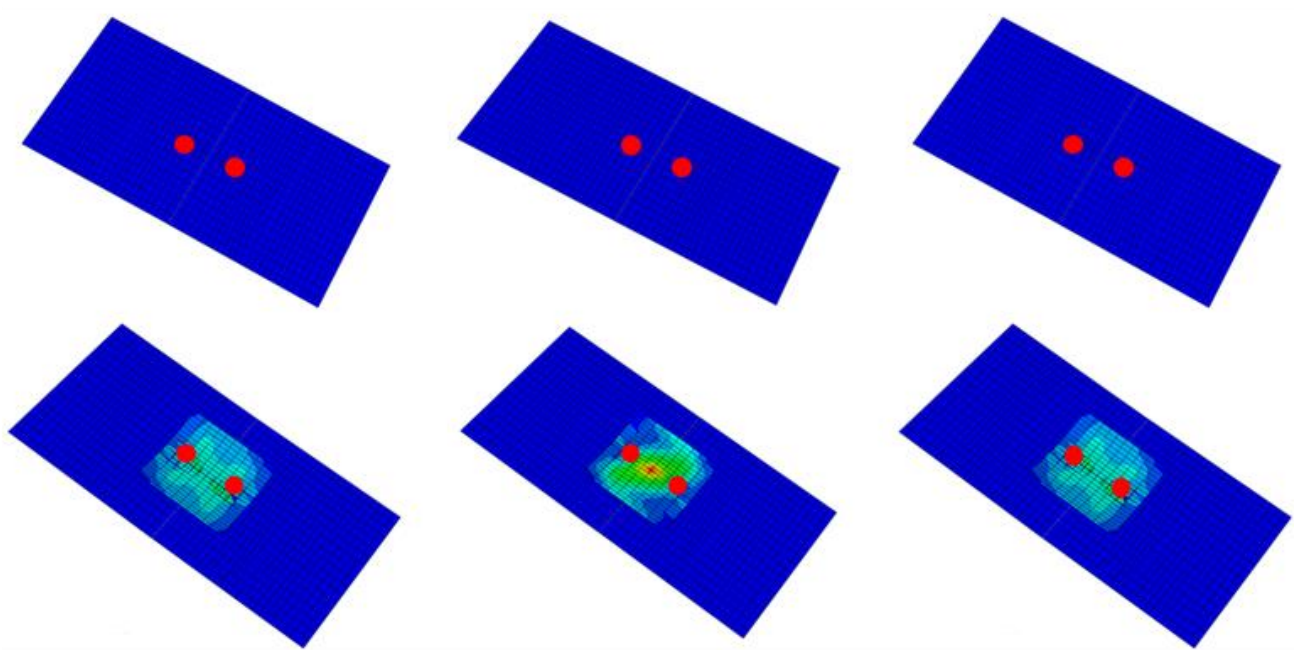

(d) (f)

Figure 5. Deformation process of one quarter of the deployable panel model. (a) Folded configuration; (b) starting to deform; (c) starting to snap through; (d) flattened configuration; (e) starting to recover; (f) flattened configuration.

Figure 6 shows the deformation process of the entire deployable panel, in which the two stable configurations show good agreement with experimental observations. The simulation procedure for the entire deployable model was similar to that of the one-quarter model. Figure $6 \mathrm{a}$ illustrates the entire deployable panel model in the folded state. Figure $6 \mathrm{~b}$ shows the entire deployable panel model in an unfolded state, but the model is still loaded. In the unstable state shown in Figure $6 c$, the position of the loaded edge exceeds the location where the second stable state is completed. As the displacement load was withdrawn, the entire deployable panel remained in the second stable configuration without a sustained external energy supply, as shown in Figure $6 \mathrm{~d}$. The simulation results showed that the deployable panel model was able to transform between the folded and flattened states, with dramatic changes in the surface area and volume. 


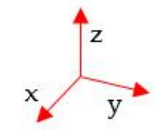

View I

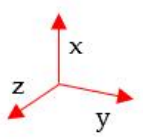

View II
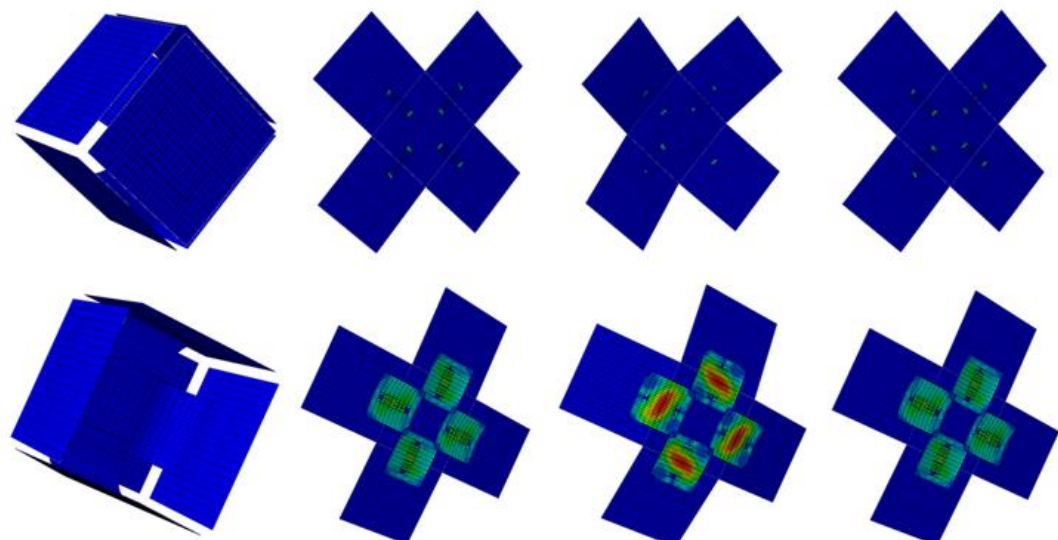

(a)

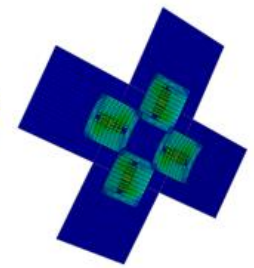

(b)

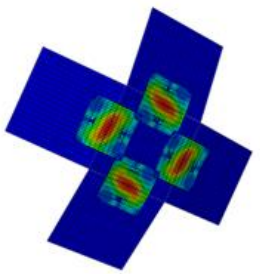

(c)

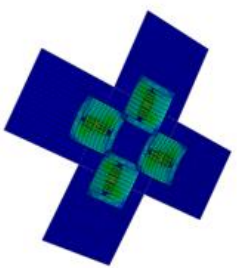

(d)

Figure 6. Deformation process of the entire deployable panel model. (a) Folded configuration; (b) unfolding state; (c) unstable state; (d) flattened configuration.

The bistable characteristics of the structure were mainly derived from the bistable characteristics of the cylindrical shell, which existed due to the inconsistent thermal expansion coefficients caused by the inconsistent layup angles of each layer of carbon fibers. According to previous simulation and experimental experience, material thickness has the greatest influence on the critical load. The structure discussed in this paper needed to have greater stiffness and stability in the unfolded state. In order to make the structure less prone to deformation, we aimed to maximize the critical load in the design.

\section{Results and Discussion}

\subsection{Mechanical Properties of the Deployable Panel Model}

Load-displacement curves reflect the mechanical properties of the deployable panel model under the action of external loading. Figure 7 shows the load-displacement curves obtained from the experiment and simulation. Both curves show that the load first increases with increasing displacement, followed by a sudden downward trend at the end of loading. This is because the snap-through process was completed and the model had transformed into the second stable configuration. After the load in the simulation curve was reduced to zero, it began to increase again. This was because the displacement load was still applied on the top edge of the model, as shown in Figure 5e. The experimental curve ends without reaching the value of zero because the interrupt condition was triggered.

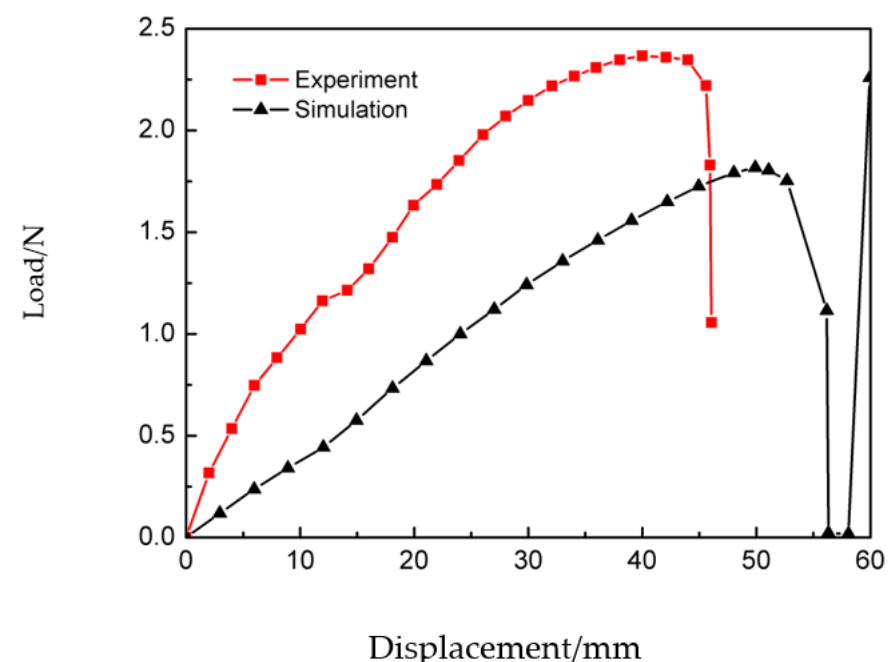

Figure 7. Simulated and experimental load-displacement curves of the deployable panel model. 
The trigger force obtained in the experiment was $2.36 \mathrm{~N}$, while the simulation value was 1.81. The trigger force of the experimental result was larger than that of the simulation result because partial energy was used to overcome the friction force between the CFRP cylindrical shell and the panel, and the accuracy of specimen manufacturing and assembly also contributed to the error. Another reason is that the material properties of the deployable panel model in different analysis methods may not have been strictly consistent.

\subsection{Effect of the Distance between Two Junctions $L_{j}$}

The influence of the distance between two junctions, $L_{j}$, when the deployable structure panels are in a flattened configuration, on the deployable models is discussed. Figure 8 shows two different stable configurations of the deployable panel model with different distances between two junctions $L_{\mathrm{j}}$. Affected by the screw bolt, the maximum value of $L_{\mathrm{j}}$ is $39.5 \mathrm{~mm}$. Five cases of $L_{j}=20,25,30,35,39.5 \mathrm{~mm}$ are considered in this example. As the distance between two junctions $L_{j}$ decreases, the greater of the two panels are unfolded. Table 3 shows that the coverage area-to-package volume ratio first decreased and then increased as the distance between the two junctions increased. The model had the largest coverage area-to-package volume ratio when the two plates were perpendicular, that is, the distance between two junctions $L_{\mathrm{j}}$ was $39.5 \mathrm{~mm}$.

(a)

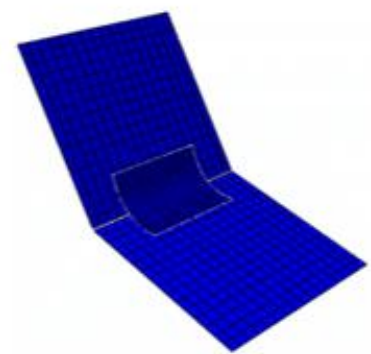

$20 \mathrm{~mm}$

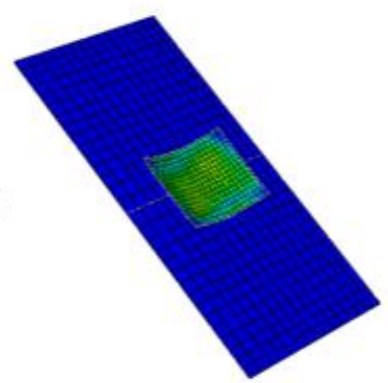

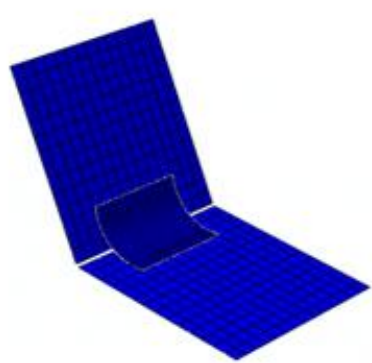

$25 \mathrm{~mm}$

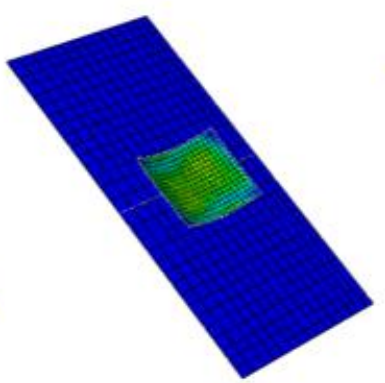

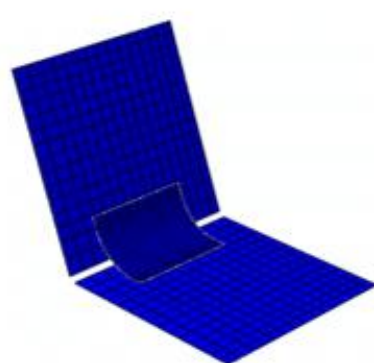

$30 \mathrm{~mm}$

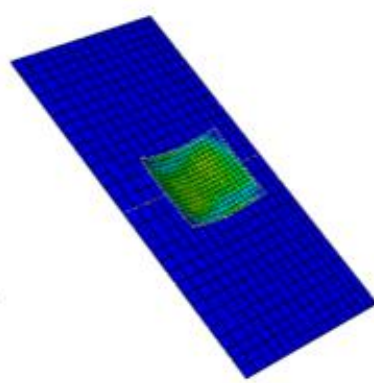

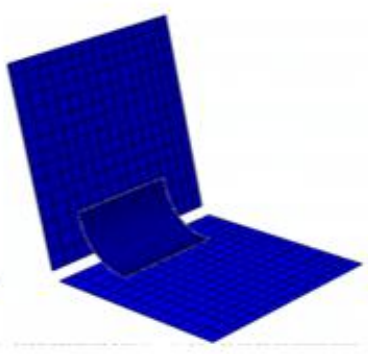

$35 \mathrm{~mm}$

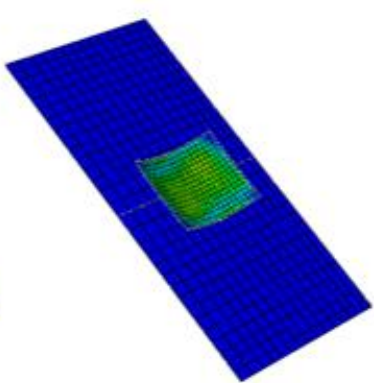

Figure 8. Different stable configurations of the deployable panel model in simulations with different values of $L_{\mathrm{j}}$. (a) folded configuration; (b) flattened configuration.

Table 3. Main technical parameters of the deployable panel model with different distances between two Junctions.

\begin{tabular}{|c|c|c|c|}
\hline $\begin{array}{c}\text { Distance between } \\
\text { Two Junctions } \\
L_{\mathbf{j}}(\mathrm{m})\end{array}$ & $\begin{array}{c}\text { Coverage Area } \\
a\left(\mathrm{~m}^{2}\right)\end{array}$ & $\begin{array}{c}\text { Package Volume } \\
v\left(\mathrm{~m}^{3}\right)\end{array}$ & $\begin{array}{c}\text { Ratio of Coverage } \\
\text { Area and Package } \\
\text { Volume } \\
\mu\left(\mathrm{m}^{-1)}\right.\end{array}$ \\
\hline $20 \times 10^{-3}$ & $405 \times 10^{-4}$ & $1252 \times 10^{-6}$ & 32.35 \\
\hline $25 \times 10^{-3}$ & $405 \times 10^{-4}$ & $1270 \times 10^{-6}$ & 31.89 \\
\hline $30 \times 10^{-3}$ & $405 \times 10^{-4}$ & $1171 \times 10^{-6}$ & 34.59 \\
\hline $35 \times 10^{-3}$ & $405 \times 10^{-4}$ & $963 \times 10^{-6}$ & 42.06 \\
\hline $39.5 \times 10^{-3}$ & $405 \times 10^{-4}$ & $729 \times 10^{-6}$ & 55.56 \\
\hline
\end{tabular}




\subsection{Effect of the Sidelength of the Deployable Panel $L_{s}$}

In this section, the influence of the sidelength of the deployable panel $L_{\mathrm{S}}$ on the trigger force of the deployable panel is discussed. Figure 9 shows two different stable configurations of the deployable panel model with different panel dimensions. Five cases of $L_{\mathrm{s}}=70, \ldots, 110 \mathrm{~mm}$ are considered in this paper. The corresponding load-displacement curves for different values of $L_{\mathrm{S}}$ are presented in Figure 10. This shows that the trigger force of the deployable panel model decreased with increasing sidelength $L_{\mathrm{s}}$. It should be noted that the force decreased dramatically to zero at the end, which means that the second stable state was obtained.

(a)

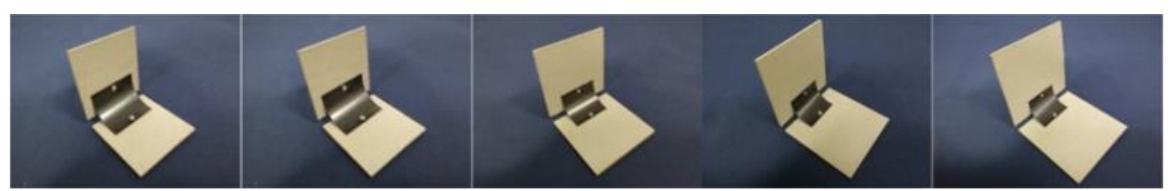

(b)

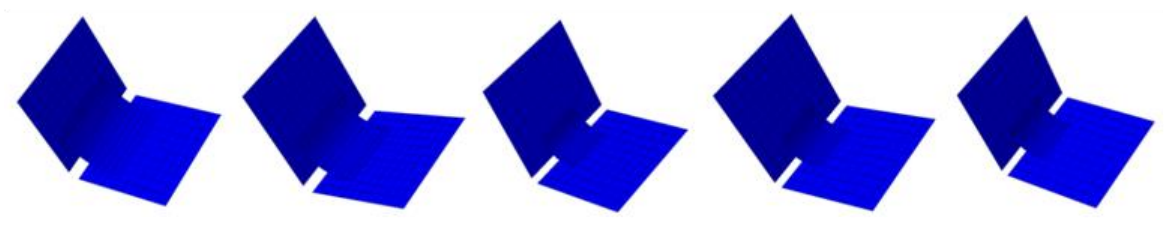

$70 \mathrm{~mm}$

$80 \mathrm{~mm}$

$90 \mathrm{~mm}$

$100 \mathrm{~mm}$

$110 \mathrm{~mm}$

(c)

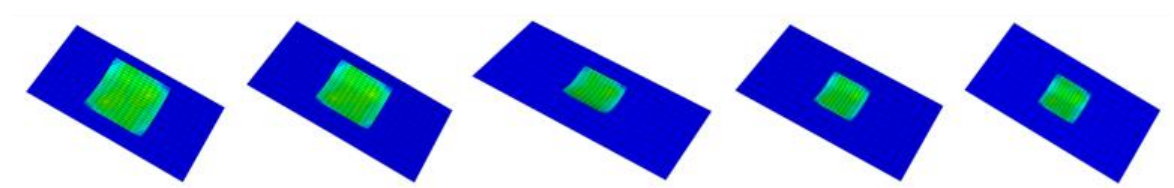

Figure 9. Different stable configurations of the deployable panel model in simulations with different dimensions. (a) Specimens of folded configuration; (b) finite element models of folded configuration; (c) finite element models of flattened configuration.

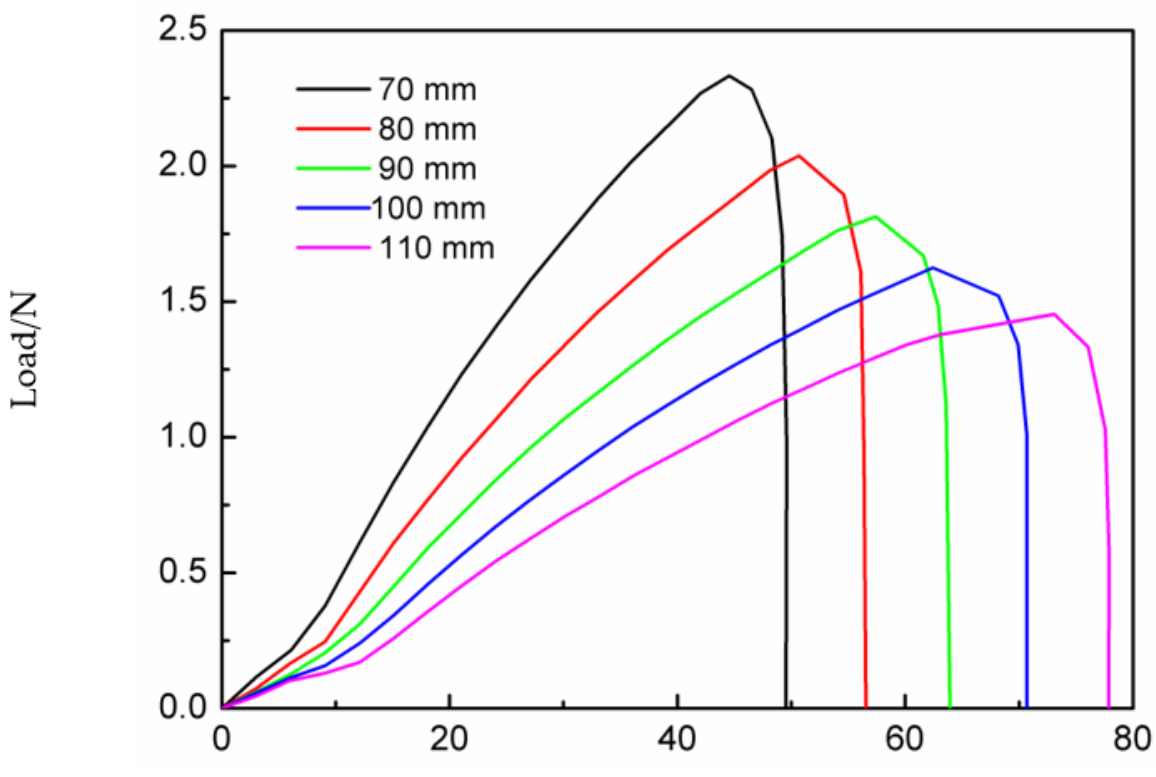

Displacement $/ \mathrm{mm}$

Figure 10. Load-displacement curves of the deployable panel model with different sizes in the simulation. 
The deployable structure specimens with different panel sidelengths were manufactured as shown in Figure 9a. The load-displacement curves of each specimen were obtained by a compression test on the universal tensile testing machine and are shown in Figure 11. The trigger forces measured in the experiments were also greater than those of the FE simulations. Table 4 presents the main technical parameters of the deployable models with different panel sidelengths. The coverage area-to-package volume ratio decreased as the panel sidelength increased.

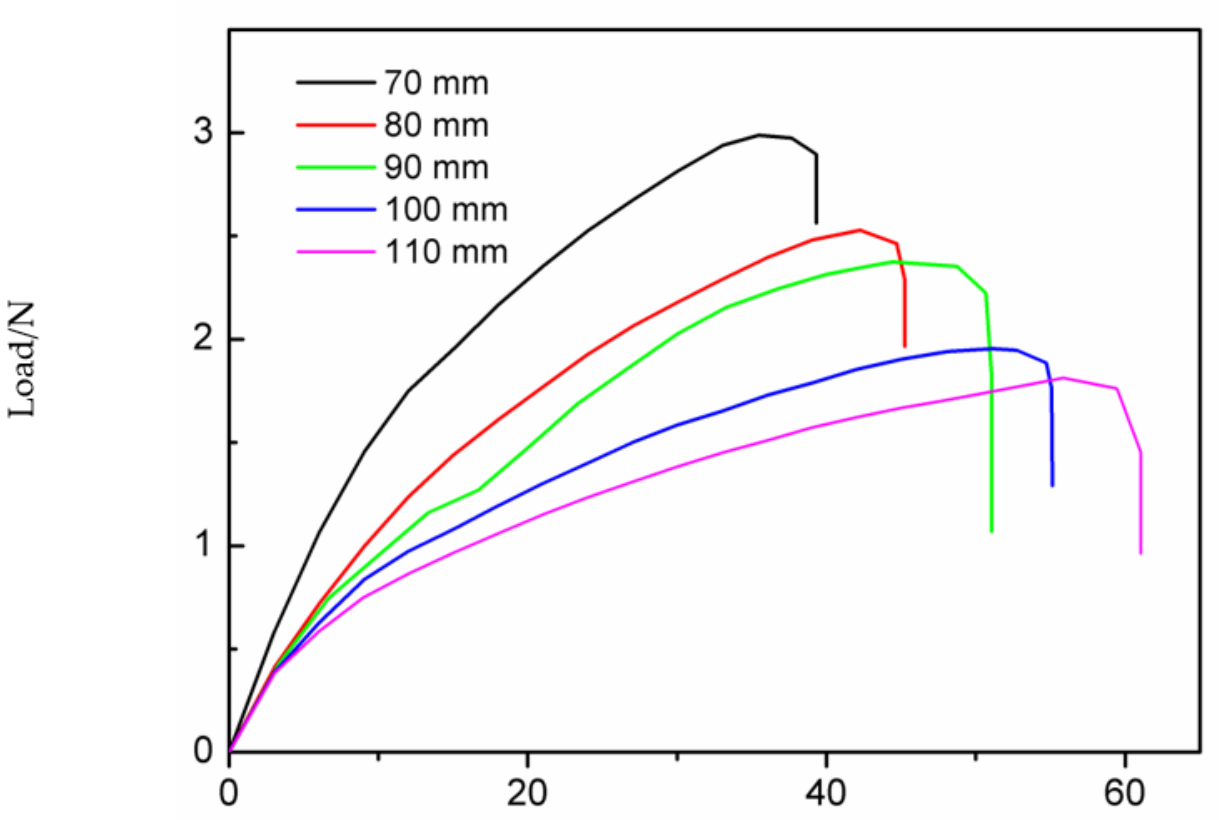

Displacement/mm

Figure 11. Load-displacement curves of the deployable panel model specimen with different sizes in the experiment.

Table 4. Main technical parameters of the deployable panel model with different panel sidelengths.

\begin{tabular}{|c|c|c|c|}
\hline $\begin{array}{l}\text { Sidelength of the } \\
\text { Deployable Panel } \\
L_{\mathrm{s}}(\mathrm{m})\end{array}$ & $\begin{array}{c}\text { Coverage Area } \\
a\left(\mathrm{~m}^{2}\right)\end{array}$ & $\begin{array}{c}\text { Package Volume } \\
v\left(\mathrm{~m}^{3}\right)\end{array}$ & $\begin{array}{c}\text { Ratio of Coverage Area and } \\
\text { Package Volume } \\
\mu\left(\mathrm{m}^{-1}\right)\end{array}$ \\
\hline $70 \times 10^{-3}$ & $245 \times 10^{-4}$ & $343 \times 10^{-6}$ & 71.43 \\
\hline $80 \times 10^{-3}$ & $320 \times 10^{-4}$ & $512 \times 10^{-6}$ & 62.50 \\
\hline $90 \times 10^{-3}$ & $405 \times 10^{-4}$ & $729 \times 10^{-6}$ & 55.56 \\
\hline $100 \times 10^{-3}$ & $500 \times 10^{-4}$ & $1000 \times 10^{-6}$ & 50.00 \\
\hline $110 \times 10^{-3}$ & $605 \times 10^{-4}$ & $1331 \times 10^{-6}$ & 45.45 \\
\hline
\end{tabular}

\subsection{Effect of the Number of Layers of Bistable CFRP Cylindrical Shells}

The influence of the geometric parameters of bistable CFRP cylindrical shells was also studied. The stacking sequences of the cylindrical shell were $\left[45^{\circ} /-45^{\circ}\right]_{2},\left[45^{\circ} /-45^{\circ} / 0^{\circ} /\right.$ $\left.45^{\circ} /-45^{\circ}\right],\left[45^{\circ} /-45^{\circ}\right]_{3},\left[45^{\circ} /-45^{\circ} / 45^{\circ} / 0^{\circ} /-45^{\circ} / 45^{\circ} /-45^{\circ}\right]$ and $\left[45^{\circ} /-45^{\circ}\right]_{4}$. Figure 12 demonstrates the influence of the number of layers of the CFRP cylindrical shell on the load-displacement curves. The results show that the trigger force of the deployable panel model increased significantly with an increase in the number of layers. This was because the bistable CFRP cylindrical shell with more layers had a higher stiffness and consequently required a greater force for the transition between the two stable states. 


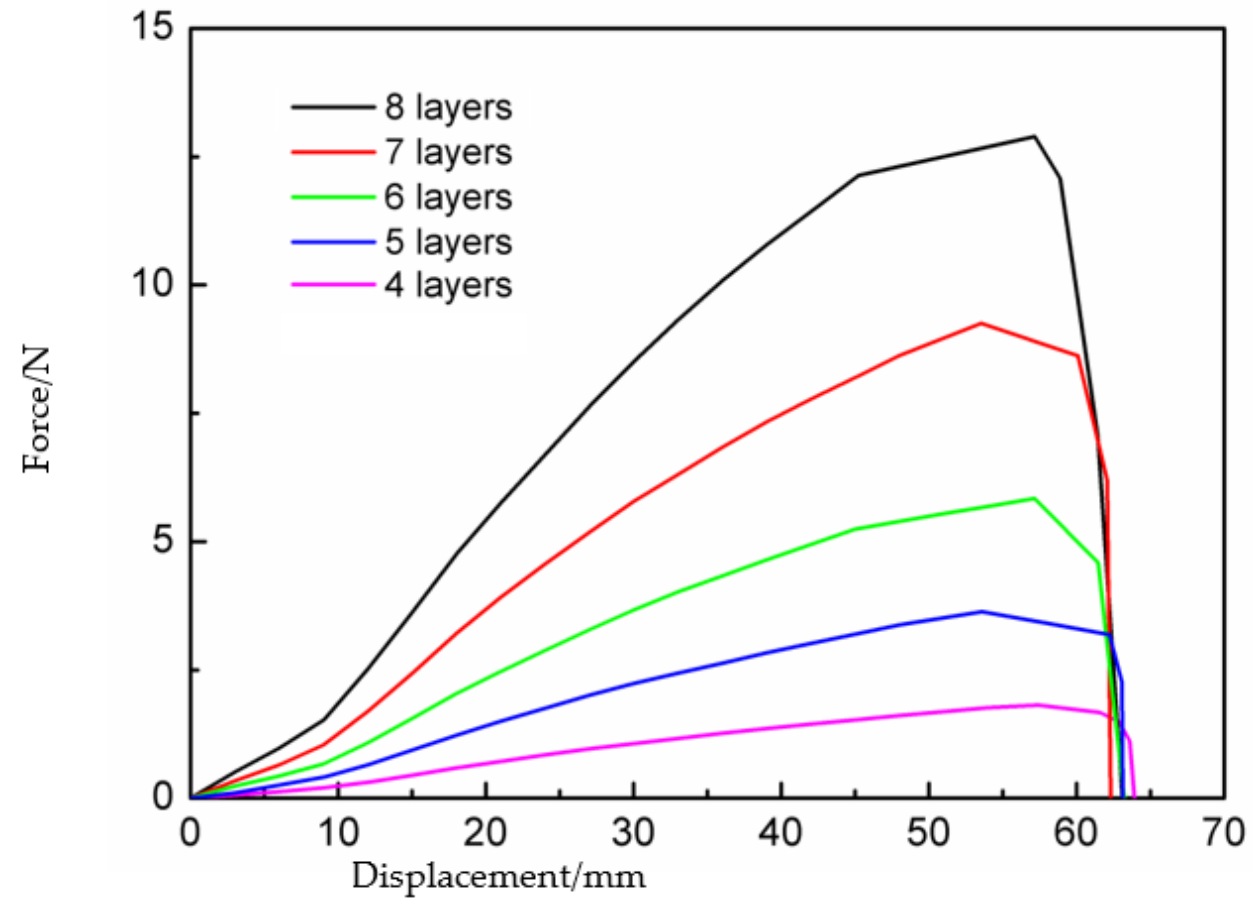

Figure 12. Load-displacement curves of the deployable panel model in simulations with different numbers of layers of the cylindrical shell.

Therefore, deployable panel models with different coverage area-to-package volume ratios and load-carrying capacities could be designed by varying the panel dimensions and geometric parameters of bistable CFRP cylindrical shells to meet the mechanical needs under various working conditions.

\section{Conclusions}

This paper presents a deployable panel structure inspired by the thick origami structure and bistable composite cylindrical shell that can remain in either a folded state (spatial) or a flattened (unfolded) state without the need for continuous external loading. The structural design of the model was given. Specimens were fabricated and assembled according to the geometric parameters based on thick origami technology and the axis shift method. In addition, finite element simulations were carried out and compared with experimental results. The error between the finite element simulation and the experimental results is less than $10 \%$. The factors affecting the deployable structure's trigger force and load-displacement curve have been discussed. The trigger force of the deployable structure increases significantly as the number of layers increases and decreases with increasing panel sidelength. The coverage area-to-package volume ratio decreases first and then increases as the distance between two junctions increases, and the coverage area-to-package volume ratio decreases with increasing panel sidelength. Both experimental and numerical results show that the proposed deployable panel model can remain either a folded (spatial) state or an unfolded (flatten) form, which sheds light on the design of space deployable structures. The deployable panel structure has a large coverage area-to-package volume ratio, which shows its application potential for solar panels. The application of this structure in solar panels is not studied in this article. In future research we will propose an overall mechanism for a feasible solar panel with this structure, and larger size cylindrical shells and plates will be considered.

Author Contributions: Data curation, Y.L.; Formal analysis, W.M.; Funding acquisition, Z.Z.; Investigation, M.S.; Writing-original draft, S.D. All authors have read and agreed to the published version of the manuscript. 
Funding: This research was supported by the National Natural Science Foundation of China (Grant Nos. 52075492, 11972323), the Zhejiang Provincial Natural Science Foundation of China (Grant Nos. LR18E050002, LD22E050009, LR20A020002, LQ21A020003).

Institutional Review Board Statement: Not applicable.

Informed Consent Statement: Not applicable.

Data Availability Statement: Not applicable.

Conflicts of Interest: The authors declare no conflict of interest.

\section{References}

1. Stevenson, A. Oxford Dictionary of English; Oxford University Press: Oxford, UK, 2010.

2. Pellegrino, S. Deployable Structures; Springer: Berlin, Germany, 2014; Volume 412.

3. Hutchinson, R.G.; Wicks, N.; Evans, A.G.; Fleck, N.A.; Hutchinson, J.W. Kagome plate structures for actuation. Int. J. Solids Struct. 2003, 40, 6969-6980. [CrossRef]

4. Ramrakhyani, D.S.; Lesieutre, G.A.; Frecker, M.; Bharti, S. Aircraft structural morphing using tendon-actuated compliant cellular trusses. J. Aircr. 2005, 42, 1615-1621. [CrossRef]

5. Fenci, G.E.; Currie, N.G.R. Deployable structures classification: A review. Int. J. Space Struct. 2017, 32, 112-130. [CrossRef]

6. Zhang, Z.; Pei, K.; Sun, M.; Wu, H.; Wu, H.; Jiang, S.; Zhang, F. Tessellated multistable structures integrated with new transition elements and antisymmetric laminates. Thin-Walled Struct. 2022, 170, 108560. [CrossRef]

7. Šekularac, N.; Ivanović-Šekularac, J.; Čikić-Tovarović, J. Folded structures in modern architecture. Facta Univ. Ser. Archit. Civ. Eng. 2012, 10, 1-16. [CrossRef]

8. Lebée, A. From Folds to Structures, a Review. Int. J. Space Struct. 2015, 30, 55-74. [CrossRef]

9. Zhang, Z.; Pei, K.; Wu, H.; Sun, M.; Chai, H.; Wu, H.; Jiang, S. Bistable characteristics of hybrid composite laminates embedded with bimetallic strips. Compos. Sci. Technol. 2021, 212, 108880. [CrossRef]

10. Zhang, Z.; Zhou, Y.; Shen, H.; Sun, M.; Chai, H.; Wu, H.; Jiang, S. Experimental study of orthogonal bistable laminated composite shell driven by magnetorheological elastomer. Compos. Struct. 2021, 271, 114119. [CrossRef]

11. Zhong, S.Y.; Zhang, X.; Gill, J.; Fattah, R.; Sun, Y.H. A numerical investigation of the airfoil-gust interaction noise in transonic flows: Acoustic processes. J. Sound Vibr. 2018, 425, 239-256. [CrossRef]

12. Jeong, D.; Lee, K. Design and analysis of an origami-based three-finger manipulator. Robotica 2018, 36, 261-274. [CrossRef]

13. Pagano, A.; Yan, T.X.; Chien, B.; Wissa, A.; Tawfick, S. A crawling robot driven by multi-stable origami. Smart Mater. Struct. 2017, 26, 11. [CrossRef]

14. Daynes, S.; Trask, R.S.; Weaver, P.M. Bio-inspired structural bistability employing elastomeric origami for morphing applications. Smart Mater. Struct. 2014, 23, 125011. [CrossRef]

15. Liber, M.; Tomov, T.E.; Tsukanov, R.; Berger, Y.; Popov, M.; Khara, D.C.; Nir, E. Study of DNA Origami Dimerization and Dimer Dissociation Dynamics and of the Factors that Limit Dimerization. Small 2018, 14, 1800218. [CrossRef] [PubMed]

16. Selnihhin, D.; Sparvath, S.M.; Preus, S.; Birkedal, V.; Andersen, E.S. Multifluorophore DNA Origami Beacon as a Biosensing Platform. ACS Nano 2018, 12, 5699-5708. [CrossRef] [PubMed]

17. Schenk, M.; Guest, S.D. Geometry of Miura-folded metamaterials. Proc. Natl. Acad. Sci. USA 2013, 110, 3276-3281. [CrossRef] [PubMed]

18. Yasuda, H.; Yein, T.; Tachi, T.; Miura, K.; Taya, M. Folding behaviour of Tachi-Miura polyhedron bellows. Proc. R. Soc. A Math. Phys. Eng. Sci. 2013, 469, 20130351. [CrossRef]

19. Fang, H.B.; Li, S.Y.; Ji, H.M.; Wang, K.W. Dynamics of a bistable Miura-origami structure. Phys. Rev. E 2017, 95, 052211. [CrossRef]

20. Hanna, B.H.; Magleby, S.P.; Lang, R.J.; Howell, L.L. Force-Deflection Modeling for Generalized Origami Waterbomb-Base Mechanisms. J. Appl. Mech. Trans. ASME 2015, 82, 081001. [CrossRef]

21. Feng, H.J.; Ma, J.Y.; Chen, Y.; You, Z. Twist of Tubular Mechanical Metamaterials Based on Waterbomb Origami. Sci. Rep. 2018, 8, 9522. [CrossRef]

22. Hanna, B.H.; Lund, J.M.; Lang, R.J.; Magleby, S.P.; Howell, L.L. Waterbomb base: A symmetric single-vertex bistable origami mechanism. Smart Mater. Struct. 2014, 23, 094009. [CrossRef]

23. Chillara, V.S.C.; Dapino, M.J. Stress-biased laminated composites for smooth folds in origami structures. Mater. Res. Express 2018, 6, 025703. [CrossRef]

24. Zhang, Z.; Liao, C.; Chai, H.; Ni, X.; Pei, K.; Sun, M.; Wu, H.; Jiang, S. Multi-objective optimization of controllable configurations for bistable laminates using NSGA-II. Compos. Struct. 2021, 226, 113764. [CrossRef]

25. Chillara, V.S.C.; Dapino, M.J. Stability considerations and actuation requirements in bistable laminated composites. Compos. Struct. 2018, 184, 1062-1070. [CrossRef]

26. Hu, J.Q.; Lin, S.; Dai, F.H. Pattern Reconfigurable Antenna Based on Morphing Bistable Composite Laminates. IEEE Trans. Antennas Propag. 2017, 65, 2196-2207. [CrossRef]

27. Zhang, Z.; Ni, X.; Wu, H.; Sun, M.; Bao, G.; Wu, H.; Jiang, S. Pneumatically Actuated Soft Gripper with Bistable Structures. Soft Robot. 2021, 9, 57-71. [CrossRef] [PubMed] 
28. Chen, Y.; Feng, J.; Sun, Q.Z. Lower-order symmetric mechanism modes and bifurcation behavior of deployable bar structures with cyclic symmetry. Int. J. Solids Struct. 2018, 139, 1-14. [CrossRef]

29. Zhang, G.; Zhang, Y.J.; Zhang, T.Q.; Rana, M. Stochastic resonance in an asymmetric bistable system driven by multiplicative and additive Gaussian noise and its application in bearing fault detection. Chin. J. Phys. 2018, 56, 1173-1186. [CrossRef]

30. Chen, T.; Bilal, O.R.; Shea, K.; Daraio, C. Harnessing bistability for directional propulsion of soft, untethered robots. Proc. Natl. Acad. Sci. USA 2018, 115, 5698-5702. [CrossRef]

31. Zhang, Z.; Li, X.; Yu, X.; Chai, H.; Li, Y.; Wu, H.; Jiang, S. Magnetic actuation bionic robotic gripper with bistable morphing structure. Compos. Struct. 2019, 229, 111422. [CrossRef]

32. Zhang, H.; Li, C.L.; Liu, G.F.; Zang, X.Z.; Jin, H.Z.; Liu, Y.B.; Zhao, J. Study of human-robot collaboration technologies of bionic robot arm in a surgery. Basic Clin. Pharmacol. Toxicol. 2016, 118, 91.

33. Sun, Q.Z.; Xing, Y.F. Exact eigensolutions for flutter of two-dimensional symmetric cross-ply composite laminates at high supersonic speeds. Compos. Struct. 2018, 183, 358-370. [CrossRef]

34. Tawfik, S.A.; Dancila, D.S.; Armanios, E. Planform effects upon the bistable response of cross-ply composite shells. Compos. Pt. A-Appl. Sci. Manuf. 2011, 42, 825-833. [CrossRef]

35. Kim, I.B.; Song-Hak, U.; Ji, T.H. Determination of local stiffness of a cross-ply composite plate with delaminations and matrix cracks. Compos. Struct. 2018, 196, 127-134. [CrossRef]

36. Lee, J.G.; Ryu, J.; Kim, S.W.; Koh, J.S.; Cho, K.J.; Cho, M. Effect of initial tool-plate curvature on snap-through load of unsymmetric laminated cross-ply bistable composites. Compos. Struct. 2015, 122, 82-91. [CrossRef]

37. Zhang, Z.; Pei, K.; Sun, M.; Wu, H.; Yu, X.; Wu, H.; Jiang, S.; Zhang, F. A novel solar tracking model integrated with bistable composite structures and bimetallic strips. Compos. Struct. 2020, 248, 112506. [CrossRef]

38. Veidt, M.; $\mathrm{Ng}$, C.T. Influence of stacking sequence on scattering characteristics of the fundamental anti-symmetric Lamb wave at through holes in composite laminates. J. Acoust. Soc. Am. 2011, 129, 1280-1287. [CrossRef] [PubMed]

39. Zhang, Z.; Li, Y.; Yu, X.; Li, X.; Wu, H.; Wu, H.; Jiang, S.; Chai, G. Bistable morphing composite structures: A review. Thin-Walled Struct. 2019, 142, 74-97. [CrossRef]

40. Wang, H.; Zhao, D.; Jin, Y.; Wang, M.; Mukhopadhyay, T.; You, Z. Modulation of multi-directional auxeticity in hybrid origami metamaterials. Appl. Mater. Today 2020, 20, 100715. [CrossRef] 